\title{
Documentation: Its Importance in Medical \& Dental Health Sectors - A Questionnaire Based Qualitative Survey Study
}

\author{
Dr. P Sridhar Reddy MDS ${ }^{1}$, Dr. Bina Kashyap MDS ${ }^{2 *}$ \\ ${ }^{1}$ Associate Professor Department of Oral \& Maxillofacial Surgery Division of Maxillofacial \& Diagnostic Sciences Buraydah Dental College, Saudi \\ Arabia \\ ${ }^{2}$ Associate Professor Department of Oral Pathology \& Microbiology Division of Maxillofacial \& Diagnostic Sciences Buraydah Dental College, Saudi \\ Arabia
}

*Corresponding author: Dr. Bina Kashyap MDS

\section{Abstract}

Aims \& Objectives: The present study was intended to know the awareness about the recording and maintenance of patient data profile by the dental and medical clinicians. Materials \& Methods: The study included google based survey analysis of questionnaire among the medical and dental clinicians. Twenty questionnaires related to knowledge, record maintenance and its advancements of collections were assessed. The answers were collected in tabulated data and statistical evaluation was done. Results: Of total 484 subjects, 131 were the dental clinicians and 353 were medical clinicians. Difference in the response was observed among the dental and medical clinicians. Data showed majority $76.86 \%$ were good in record maintenance, $10.74 \%$ were better and only $11.98 \%$ were considered to be very good. Conclusion: Records should be durable and accessible but safe from tampering or falsification. Also the medical and dental professionals should be stressed to use of health information systems for data management, to ensure the patients better health.

Key words: Awareness, Clinicians, Dental, Medical, Record.

Copyright @ 2019: This is an open-access article distributed under the terms of the Creative Commons Attribution license which permits unrestricted use, distribution, and reproduction in any medium for non-commercial use (NonCommercial, or CC-BY-NC) provided the original author and source are credited.

\section{INTRODUCTION}

In today's world, health services have become a prime important aspect due to diverse nature of diseases and its progress. The various diseases, its development, signs and symptoms, prevention etc. have been well documented in the textbooks and available at ease to general public through social medias. An understanding of the nature of the diseases is a continuous process for health care specialists due to its varied presentation and treatment approach. This makes health care specialists to assess every disease with care and document it as a source of evidence in the delivery of care.

Data record is also referred to as the patient chart. It is defined as the official office document that records all diagnostic information, clinical notes, treatment performed and patient related communications that occur in the dental office, instructions for home care and consent to treatment. Data is a set of values of qualitative and quantitative variables that gives details of a patient's management. They have the potential to provide a database for research, effective communication among health professionals towards quality of care assessments, defense against malpractice, improve the quality of health care and help control costs through improved efficiency $[1,2]$.

The world's first data storage system was discovered about 5,500 years ago, at time when early cities were flourishing in Mesopotamia. Christopher Woods, a professor at the University of Chicago's Oriental Institute, identified \& said that the clay balls represent the world's 'very first data storage system'. The balls were created with clay which were called as 'envelopes', are hollow and contain different geometric shapes or 'tokens'. The token inside the ball represents specific measuring systems and contains 14 different shapes, including spheres, pyramids, ovoid's, lenses and cones. All of the clay balls contain, on the outside, one seal running through the middle and usually two seals, running above and below. Researchers believe the seal in the middle represents the 'buyer' or recipient. The polar seals would represent the 'seller' [3-5].

Documentation of the patient's clinical record gives a lot of information about the care given and their 
response. In the developed and developing countries there are various types of data recording which includes patient health records, records of private patients, accident \& emergency, birth and all other register, theatre registers and minor operating registers, administrative records, X-ray and imaging reports, photographs \& slides, microfilm, audio \& video tapes, cassettes, CD-ROM etc., e-mails, computerized records and scanned records and text messages. Documentation serves best educational tool in the educational institutes [6].

There are 3 methods of data collection. 1) Paper based systems: Information is recorded on paper $\&$ data are transferred from paper for analyses or use. 2) Computerized data: Data are entered into a computer (often from paper) from where they can be analyzed \& retrieved. 3) Electronic record management: This is the most advanced level combines the use of computerized data with the ability to electrically transparent it to multiple users in multiple locations [6]. There are some published guidelines provided by American Dental Association for the content, quality and accessibility of data. The adoption of these guidelines by the clinicians in everyday practice or academicians or by the educational institutes is obscure. Hence, with the advancement in the storage of data in the developed countries, the present study aims to know the awareness about the recording and maintenance of patient data profile by the medical and dental clinicians in developing country like India.

\section{MATERIALS AND METHOD}

The study included closed and open ended Google based questionnaire survey among the medical and dental clinicians. Twenty questions related to knowledge of documentation, maintenance, its advancements of collections and its purpose of collection were formulated and distributed. The study was conducted for six months and the responses were collected in tabulated data. All the responses were scrutinized and the statistical validation were put forward and analyzed in Graph Pad Prism software.

\section{RESULTS}

The data collected included 484 subjects. Of total 484 subjects, 131 were the dental clinicians and
353 were medical clinicians. Demographic data obtained showed total female participants in the study were $28.1 \%$ and $71.9 \%$ of male participants. $32 \%$ of participants were more than 55 years of age followed by $28.3 \%$ in $45-55$ years, $27.5 \%$ in $35-45$ years and $12.6 \%$ in $25-35$ years of age [Graph $1 \& 2$ ].

All the questions pertaining to the data collection \& record maintenance were answered by the subjects. $100 \%$ agreed response was obtained by dental clinicians for recording the patient's data in clinic, importance of data recording and the difference in recording data in private institute and clinic. Medical clinicians showed varied opinion where $98.87 \%$ responded for patient's data recording, $86.40 \%$ for importance data recording and $97.17 \%$ agreed in the difference of data recording.

$69.46 \%$ \& $76.20 \%$ of dental \& medical clinicians follow case Performa in clinic and overall $69.83 \%$ follow some working guidelines for data recording and maintenance. $77.80 \%$ of the subjects were aware of the available software's for data recording and only $37.22 \%$ follow both computerized as well as written format of recording patient's data.

$87.02 \% \& 78.75 \%$ of the dental \& medical clinicians preserve the patient's data for less than 2 years whereas $12.98 \%$ of dental and $21.24 \%$ of medical clinicians were accumulating the data for 2 to 5 years. Data analysis about recording different type of cases showed similar results where predominant cases recorded by both included special cases $(60.74 \%)$, all the cases $(31.81 \%), 3.72 \%$ of major cases and the minor cases were observed to be recorded by the medical clinicians $(2.27 \%)$ but dental clinicians did not show any record of the minor cases.

While grading themselves, individual clinicians irrespective of dental and medical field, majority $76.86 \%$ graded them self to be good in data collection \& record maintenance, $10.74 \%$ considered them to be better and only $11.98 \%$ considered them to be very good. $32 \%$ of the subjects with clinical experience of more than 20 years and more than 55 years of age appeared to be in very good grade in maintaining the documentation [Graph 3].

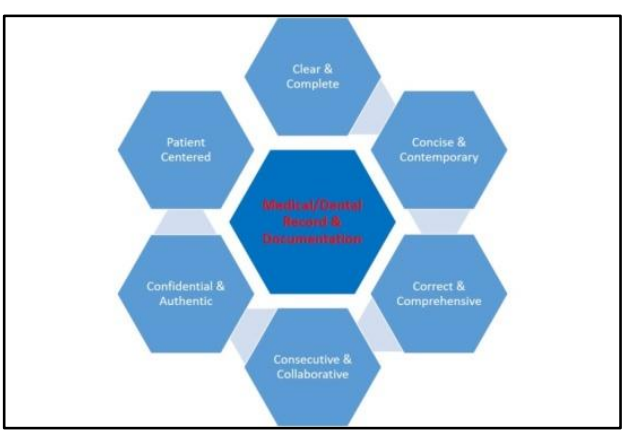

Fig-1: Working guideline for documenting the documentation 


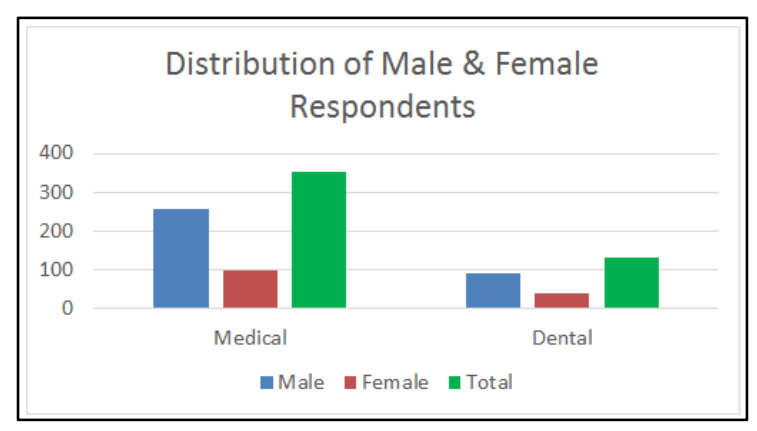

Graph-1: Total distribution of male and female dental and medical clinicians

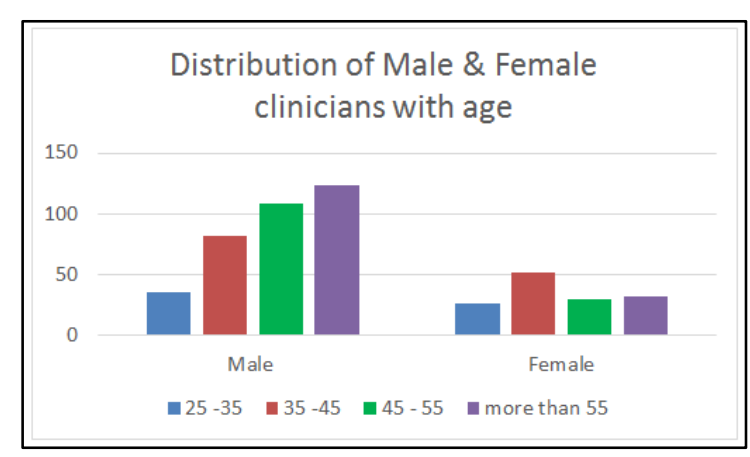

Graph-2: Distribution of male and female dental and medical clinicians with respect to age

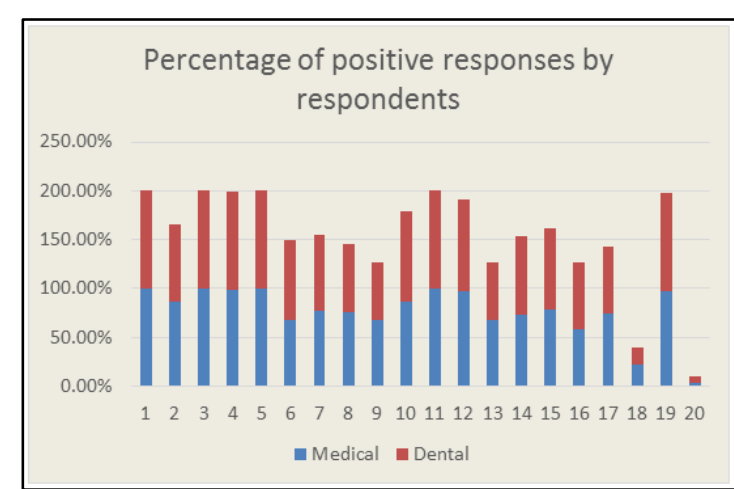

Graph-3: Overall positive responses of the dental and medical clinicians

\section{DISCUSSION}

Precise and comprehensive dental or medical records do not imply the provision of exceptional treatment but they do provide an opportunity to assess the value of care provided. The epidemiologic studies concerning oral \& general health, diseases, cancers and health awareness programmes have steadily increased within the past few years. The aims of such studies are diverse $[1,2]$, with all these studies the intra- and interexaminer variabilities can be reduced if one standardizes not only the diagnostic criteria but also the recording methods $[4,8,9]$.

Documenting the patient's chart, as an official office document includes all the treatment done and all patient-related communications that occur in the clinic. The patient's record provides continuity of care for the patient and is critical in the event of a malpractice insurance claim. Not only this the other uses includes: best possible care, evaluation of patient care, an information to a new doctor attending the same patient, Medico legal proceedings, identification and forensic medicine/dentistry [10].

The patient data is mostly recorded in the form of files, volumes, folders, bundles, maps, plans, charts and etc. The data may contain tests, images, sounds and /or paper; data must contain sufficient information to support the diagnosis. There are 3 modes of data recording - a) Paper based system b) Computerized data and, c) Electronic record management $[5,6]$. Low income countries have a higher use of paper for data recording as it is easy to use, less time consuming, economical, can be used by any person and additional technical skills not required. But the major disadvantage observed with this storage system includes a large space and difficulty in retrieval. Computerized data is widely used in developing and developed countries because it provides good storage \& occupies less space, easy to retrieve and contains full data. The presence of skilled person for data recording, costly equipment and back up of the data is necessary to maintain the computerized data. Electronic record management is a system that manages electronic records throughout their life cycle from creation through to their disposal or permanent retention. There are many benefits of electronic record management such as, improved data collection, staff productivity, visitor satisfaction with the services provided, improved quality of care with reduced medical errors and efficient way of use for the staff. The major disadvantage of electronic record management includes time consuming, slow assess of data and decreased quality of patient doctor interaction [9].

In the present study the records were maintained by all the subjects in the paper as well as in the computerised form. Hence this represents mixed economy state as suggested by World Health Organization (WHO). According to WHO, in low economic countries there is higher use of paper and low use of electronic format. Paper and electronic records co-exist in mixed economy whereas few countries and high income countries have reported the wide use of electronic formats in data recording and maintenance $[2,8] .52 .5 \%$ of clinicians were not able to provide proper documentations due to their busy settings, balancing multiple information sources, competing tasks and decreased amount of time available for patient's care. Remaining $47.5 \%$ of clinicians were able to record the complete data by utilizing dental assistants/hygienists as documenters. Most of the informal assessments regarding documentation revealed problems like incomplete information on patient care, lack of standard, insufficient time $\&$ training and no reviews to evaluate documentation. The present study supports the need for improvement in order to simplify 
easy entry of clinical information and minimize dismissal in correlation with the study by Tokede et al. [11].

Different opinion was observed among the clinicians in recording the type of case. Most of the clinicians preserve and record only special cases (includes cases which are different in clinical presentation, history and line of treatment) followed by major cases (if operated or treated by the main doctor). Maintaining the record of all the patients reporting for the treatment was very less among the subjects. It seems reasonable that if clinicians believe that recording a general information is unimportant, they will be less likely to do so and this results in incomplete data. This could also be due to the competitive nature among the clinicians to treat patients or due to time taking procedures or due to lack of knowledge of newer system for data storage. The survey demonstrated that the greatest barrier to obtain patient information is the lack of resources, lack of skilled health informatics professionals and commercial and competitive nature.

Records may not be retained or maintained for long periods. According to public records act, the records which are still in current use should be retained legally. Under section 33 of data protection act, records must be maintained for more than 30 years. But according to ADA data records must be maintained for a minimum period of 7 years whereas WHO preferred for a minimum of 3 years. In the present study many of the health professionals take a brief case history and are not maintaining or preserving the data. In the present study, most of the clinicians preserve data for at least 2 -5 years, if recorded by computerized mode and below 2 years, if by paper based mode. Electronic mode of recording was not observed in our survey, though $17.9 \%$ of subjects were aware of this system of documentation $[6,11]$.

Documentation of medical/dental records and clinical documents follow some general guidelines as suggested by the governing bodies like ADA, WHO, AMA, ANA etc. it should be objective, specific, clear \& consistent, confidential, include all relevant information and should also record errors [Figure 1]. Documentations provides range of advantages such as: 1) Acts a means of professional responsibility and accountability 2) Provides reliable record of patient 3) It is a legal document 4) Basis to evaluate quality of patient's care 5) As a teaching and research scientific aid 6) As a means of communication 7) Helps in treatment plan and budgeting 8) Provides documents for insurance and re-imbursement.

\section{CONCLUSION}

Documentation provides comprehensive patient information and encouragement to professionals to improve the use of health information systems so as to ensure patients better health. There are various challenges to be admitted like shortage of staff, inadequate knowledge about documentation, different documentation requirements in different sectors and unavailability of materials for documentation. With the finding of the present study we conclude by suggesting the following points: 1) Performa for recording the complete data of the patient must be standardized 2) Electronic data maintenance is utmost important for recording, maintenance and retrieval 3) Storage of the data should be given utmost importance in future 4) There is a need for training on importance of documentation. Further studies including various validated survey and Delphi process, must be included to assess the documentation awareness in educational institute, private sectors and other health care sectors.

\section{REFERENCES}

1. Pieper, K., Klar, R., \& Kessker, P. (1981). Use of a microcomputer for recording dental epidemiologic data. Community dentistry and oral epidemiology, 9(4), 178-181.

2. World Health Organization. Expert Committee on Dental Health. (1962). Standardization of Reporting of Dental Diseases and Conditions: Report (No. 242). World Health Organization.

3. Davies, J. (1995). The Christian warrior in the twentieth century. Edwin Mellen Press.

4. Marthaler, T. M. (1966). A standardized system of recording dental conditions. Helv Odontol Acta, 10, $1-18$.

5. Records Management: NHS Code of Practice Part 1. (1996), Department of Health. Page no.1-96.

6. Dental records: American Dental Association. (2007). Available on https://www.ada.org/ /media/ADA/Public\%20Prog rams/Files/MPRG_Dental_Records.pdf?la=en

7. Health care records - Documentation and Management. Available on https://www1.health.nsw.gov.au/pds/ActivePDSDo cuments/PD2012_069.pdf

8. Davis, G. N., \& Cadell P. B. (1973). Four investigations to determine the reliability of cariesrecording methods. Scand. J. Dent. Res 81: 1-11.

9. Moller, I. J., \&. Poulsen, S. (1973). A standardized system for diagnosing, recording and analyzing dental caries data. Scand. J. Dent. Res 57: 1-11.

10. Rudman, W. J., Hart-Hester, S., Jones, W. A., Caputo, N., \& Madison, M. (2010). Integrating medical and dental records: a new frontier in health information management. Journal of AHIMA, 81(10), 36-39.

11. Tokede, O., Ramoni, R. B., Patton, M., Da Silva, J. D., \& Kalenderian, E. (2016). Clinical documentation of dental care in an era of electronic health record use. Journal of Evidence Based Dental Practice, 16(3), 154-160. 